\title{
In Vivo Intestinal Bicarbonate Transport in Infant Rats
}

\author{
M. K. YOUNOSZAI ${ }^{3 \cdots}$ ANI) J. E. ROBILLARD \\ (iastroenterology and Renal Research Laboratories, Department of Pediatrics. College of Medicine. University of \\ Iona. Lowa (it) Lowa. US.A
}

\begin{abstract}
Summary
Transport of bicarbonate $\left(\mathrm{HCO}_{3}{ }^{-}\right)$was studied in segments of the jejunum and ileum in two-, three-, and eight-wk-old rats using an in vivo, one-pass perfusion technique. From isotonic solutions the net absorption of $\mathrm{HCO}_{3}{ }^{-}(\mu \mathrm{mol} / \mathrm{hr} / \mathrm{g} \mathrm{dry} w \mathrm{wt})$ in the jejunal segments was about twice as great $(P<0.01)$ in the two- and three- as in the eight-wk-old rats. In ileal segments, $\mathrm{HCO}_{3}^{-}$ transport was quite variable; in the two- and three-wk-old rats, there was net absorption, whereas in the eight-wk-old rats, there was net secretion. In both segments, net absorption was unaffected by addition of glucose $(5 \mathrm{mmoles} / \mathrm{liter})$, or acetazolamide (10 mmoles/liter) to the perfusion solution. Perfusion of a hypertonic solution $(500 \mathrm{mOsmoles} / \mathrm{kg})$ through the segments of the two-wkold rats induced metabolic acidosis, which was associated with net secretion of relatively large amounts of bicarbonate into the lumen of both segments. Perfusion of the hypertonic solution in the eightwk-old rats did not change blood acid-base status. In these rats, net absorption of bicarbonate in the jejunum was decreased, and net secretion in the ileum was enhanced in comparison to values noted during perfusion of the isotonic solution.
\end{abstract}

\section{Speculation}

From results of the present study of segments of the jejunum and the ileum, it cannot be assumed that the excessive loss of bicarbonate from the small intestine can explain the metabolic acidosis associated with infantile diarrhea. However, if studies of the colon also show excessive loss of bicarbonate during osmotic diarrhea, they will lend further support to the assumption that the loss of bicarbonate from the small and large intestine is a major cause for the metabolic acidosis noted in infants suffering from osmotic diarrhea.

During in vivo perfusion of an isotonic solution, rates of absorption of water, sodium, chloride, and bicarbonate were greater in the jejunum and in the ileum of 2-wk-old than in corresponding segments of 8 -wk-old rats (17). Under similar condition of in vivo perfusion, experimentally induced osmotic diarrhea caused greater losses of water, sodium, and chloride in the intestine of infant than in adolescent rats (19). The hasis for these age-related differences in intestinal transport of water and electrolytes is not known However. the findings suggested that the permeability of the intestinal mucosa to water and electrolytes may be greater in infants than in older rats. This may partly explain why infants are more prone than adults to develop dehydration, electrolyte imbalance, and acidosis during episodes of diarrhea. The purpose of the present study was to investigate further transport of bicarbonate in the jejunum and ileum of 2-wk-old (suckling), 3-wk-old (weanling), and 8-wk-old (adolescent) rats and to determine its importance in the development of acidosis during experimentally induced osmotic diarrhea.

\section{MATERIALS AND METHODS}

Two- (14- to 15-day-old). 3- (21- to 22-day-old), and 8- (56-dayold) wk-old male albino rats were used for the studies. The rats were obtained from mothers with known sperm-positive data purchased from Biolab Corp. (St. Paul. MI). At the time of study, the rats were anesthetized with a mixture of ethylurea $(K \& K$ Laboratories, Inc., Plainview, NY) and phenobarbital (6:1) given IP as injections and placed on heating pads. The abdominal cavity was opened. and the temperature of the peritoneal cavity was monitored and maintained at 36 to $37^{\circ} \mathrm{C}$. Segments (10) to $15 \mathrm{~cm}$ ) of the jejunum (just distal to the ligament of Treitz) and ileum (just proximal to the ileocecal junction) were rinsed with $50 \mathrm{ml}$ of isotonic solution of sodium chloride ( $\mathrm{NaCl}, 154 \mathrm{mM})$ and then flushed with $100 \mathrm{ml}$ of air. Inlet and outlet cannulae were inserted into these segments and tied in place. The intestine adjacent to the cannulated segments were tied with ligatures. The intestine was replaced into the peritoneal cavity, and the cannulated segments were perfused. The procedures used have been described in detail in previous publications $(18,19)$.

Four different solutions were used. The solutions were isotonic (300 mOsmoles $/ \mathrm{kg}$ ) containing bicarbonate or free of bicarbonate or hypertonic $(500 \mathrm{mOsmoles} / \mathrm{kg}$ ) containing bicarbonate or free of bicarbonate. The isotonic solutions with bicarbonate contained per liter: 140 mmoles of sodium. 5 mmoles of potassium. 120 mmoles of chloride, and 25 mmoles of bicarbonate. The isotonic solutions free of bicarbonate contained per liter the same amounts of sodium and potassium and 145 mmoles of chloride. The osmolatity of the solutions was adjusted by adding enough mannitol to achieve an osmolality of 295 to $302 \mathrm{mOsmoles} / \mathrm{kg}$. The composition of the hypertonic solutions was the same as the ones described above except that to each was added an extra 200 mmoles of mannitol (Fisher Scientific Co.. Pittsburg. PA) to attain an osmolality of $500 \mathrm{mOsmoles} / \mathrm{kg}$. All solutions contained 20 $\mathrm{mg} / \mathrm{liter}$ of phenol red as nonabsorbable marker for volume change. For the study of a given solution, five to seven rats were used at each age period. The effect of $D$-glucose and acetazolamide on bicarbonate transport was evaluated by perfusing segments of separate groups of rats with solutions identical to the isotonic solutions with bicarbonate, with the exception that the solutions contained 5 mmoles/liter of I)-glucose (Fisher Scientific (o. Pittsburg. PA) or $10 \mathrm{mmoles} / \mathrm{liter}$ of acetazolamide (Lederle L.aboratories Div.. American Cyamamide Co.. Pearl River. NY) replacing equivalent amounts of mannitol. The unidirectional movement of bicarbonate across the intestinal brush border was costi mated in a separate group of rats whose intestinal segments were perfused with the isotonic solution with bicarbonate to which was also added tracer $\mathrm{NaH}^{14} \mathrm{CO}_{3}$ (New England Nuclear. Boston. MA: $5 \mathrm{mCi} / \mathrm{mmole})$. The specific activity of ${ }^{14} \mathrm{C}$-labeled sodium bicarbonate in this perfusion solution was $40000 \mathrm{dpm} / \mu$ mole of $\mathrm{NaHCO}_{3} . \mathrm{HCO}_{3}$ is in equilibrium with $\mathrm{H}_{2} \mathrm{CO}_{3}$ and $\mathrm{CO}_{2}$ and movement of ${ }^{14} \mathrm{C}^{-}$-labeled $\mathrm{HCO}_{3}$ out of the lumen could have been as ${ }^{14} \mathrm{CO}_{2}, \mathrm{H}_{2}{ }^{1 .} \mathrm{CO}_{3}$ and/or as $\mathrm{H}^{14} \mathrm{CO}_{3}$. Inasmuch as it is possible that a portion of the ${ }^{14} \mathrm{C}^{-}$-labeled $\mathrm{HCO}_{3}$ reentered the lumen. the rate of disappearance of ${ }^{14} \mathrm{C}$ radioactivity was only an approximate value for the unidirectional movement of labeled ${ }^{1.4} \mathrm{C}$ out of the lumen, be it transported as $\mathrm{CO}_{2}, \mathrm{H}_{2} \mathrm{CO}_{3}$. and/or as $\mathrm{HCO}_{3}$. For the sake of simplicity, the rate of transport of ${ }^{14} \mathrm{C}$ was taken as indicating the unidirectional flux of bicarbonate

The solutions containing bicarbonate were bubbled with a gas 
mixture of $5 \% \mathrm{CO}_{2}$ and $95 \% \mathrm{O}_{2}$ to attain a $\mathrm{pH}$ of about 7.4 and a PCO, of about $40 \mathrm{~mm} \mathrm{Hg}$ just prior to perfusion. Glass reservoirs, tubes, and collecting syringes were used to minimize the escape of $\mathrm{CO} .2$ from the system.

All solutions were perfused (one pass) at the rate of $0.3 \mathrm{ml} / \mathrm{min}$. The solution perfused over the first 60 -min period was discarded. and that perfused over the next $60 \mathrm{~min}$ was collected separately during three consecutive 20 -min periods. After the perfusion period, the perfused segments were stripped from the mesentry, and their contents was emptied by gentle pressure of the forefingers placed in the middle and drawn towards the edges. After length and wet weight were determined. the segments were cut open along the mesenteric line, and the mucosa was scraped with the edge of a microscope slide. The mucosal scrapings were dried in a vacuum oven at 90 to $95^{\circ} \mathrm{C}$ for $24 \mathrm{hr}$ and dry weight was measured.

Immediately after the perfusion period, in the perfusion solutions and the perfusates collected, $\mathrm{pH}$ and $\mathrm{PCO}$., were measured at $37^{\circ} \mathrm{C}$ using a Radiometer PHM $72 \mathrm{MK} 2$ (Radiometer. Copenhagen) acid-base analyzer with appropriate $\mathrm{pH}$ and $\mathrm{PCO}$. electrodes. Total $\mathrm{CO}$. content was determined using a Natelson Microgasometer (Micrometric Instrument $\mathrm{Co}$. Cleveland, $\mathrm{OH}$ ). Bicarbonate concentration in the solutions was calculated from total $\mathrm{CO}_{2}$ content, $\mathrm{pH}$, and $\mathrm{PCO}_{2}$ of the solutions using the Henderson Hasselbalch formulae. Radioactivity of ${ }^{14} \mathrm{C}$ was determined in a Beckman LS 300 Liquid Scintillation Spectrometer (Beckman Instruments, Inc.. Irvin. (A), and phenol red was determined as described by Schedl and Clifton (13).

Transport of bicarbonate $\left(\mathrm{HCO}_{3}\right)$ was calculated from the following formula:

$$
\mathrm{T}=\mathrm{V}_{1}\left(\left[\mathrm{HCO}_{3}\right]_{1}-\left[\mathrm{HCO}_{3}\right]_{1} \cdot \mathrm{PR}_{1} / \mathrm{PR}_{\mathrm{t}}\right)
$$

where $\mathrm{T}$ is net transport of $\mathrm{HCO}_{3}$ in $\mu$ mole $/ 20 \mathrm{~min}: \mathrm{V}$ is volume of fluid perfused during a 20 -min perfusion period in $\mathrm{ml}:\left[\mathrm{HCO}_{3}{ }^{-}\right]$ is concentration of bicarbonate in $\mu \mathrm{mole} / \mathrm{ml}$ : $\mathrm{PR}$ is concentration of phenol red in perfusion fluid in $\mu \mathrm{g} / \mathrm{ml}$; i refers to initial values in the perfusion fluid before perfusion; and $f$ refers to final values in perfusates collected. A positive $T$ was considered as indicating net absorption, and a negative $T$ was considered as indicating net secretion of bicarbonate into the lumen of the perfused segments. I ransport of water was calculated from change in concentration of phenol red during perfusion.

Disappearance of ${ }^{1 /} \mathrm{C}$ radioactivity from the lumen was taken as approximating lumen-to-mucosa (LM) flux of bicarbonate and was determined using the following formula:

$$
\mathrm{LM} \text { flux }=\mathrm{V}_{1}\left(\mathrm{dpm}_{1}-\mathrm{dpm}_{\mathrm{f}} \cdot \mathrm{PR}_{1} / \mathrm{PR}_{\mathrm{f}}\right) / \mathrm{dpm} \mathrm{m}_{1} \cdot\left[\mathrm{HCO}_{\mathrm{s}}\right]_{1}
$$

where LM flux is $\mu$ mole $/ 20 \mathrm{~min}, \mathrm{dpm}$ is ${ }^{~}{ }^{4} \mathrm{C}$ disintegrations per min per $\mathrm{ml}$ of the perfusion solution, and $\left[\mathrm{HCO}_{3}\right]$ is concentration of $\mathrm{HCO}_{3}$ in perfusion solutions $(\mu \mathrm{mole} / \mathrm{ml})$. The other symbols have the same meaning as described above. The mucosa-to-lumen
(ML) flux of bicarbonate was calculated as the difference between LM flux and net absorption.

During the last hr of perfusion, steady state conditions had been achieved, because in all rats the values for the transport of bicarbonate during each of the three 20 -min collection periods did not vary by more than $22 \%$ of each other in the jejunal as well as in the ileal segments perfused. The corresponding values for transport rates and the fluxes were combined for the three collection periods and expressed as $\mu$ mole $/ \mathrm{hr}$. So that we would be able to compare bicarbonate transport in the segments of the rats at the three age periods, the absorption rates were normalized for the wet weight of the segment or the wet or dry weight of the scraped mucosa.

\section{STATISTICAL. ANALYSIS}

The unpaired student $t$ test was used to compare mean values between corresponding segments of the control and test rats, and the paired $t$ test was used to compare mean values between segments in each group of rats. A value of $P<0.05$ was taken as indicating a statistically significant difference between the corresponding mean values $(8)$.

\section{RESULTS}

Because in the studies of the different solutions body weight and measurements of the segments perfused were similar in the rats at each age period, they were combined, and the means for each age period are shown in Table 1. Intestinal segment wet weight and $w t: \mathrm{cm}$ length ratios were severalfold greater in the 8 than in the 2- and 3-wk-old rats. The mucosal scrapings, in the 2wk-old rats formed around $50 \%$, and in the 8 -wk-old rats it formed about $70 \%$ of the full-thickness segment weight. This suggested greater mucosal epithelial (functional) mass per unit length of intestine in the older than in the younger rats. Water content of the segment mucosa was usually greater in the 8 - than in the 2 and 3 -wk-old rats.

\section{CHANGIES IN ACID-BASE STATUS OF PERFUSATES}

Changes During Perfusion of the Isotonic Solution with Bicarbonate. In the jejunal segments at all three age periods. perfusion solution total $\mathrm{CO}_{2}$ content decreased and its $\mathrm{PCO}$ increased both by about 8 to $15 \%$ of initial values $(P<0.05)$. In the ileal segments, perfusion solution total $\mathrm{CO}$, content did not change significantly in the 2- and 3-wk-old rats, but in the 8-wk-old rats, perfusion solution total $\mathrm{CO}_{2}$ content and $\mathrm{PCO}_{2}$ increased by about $8 \%$ of initial values $(P<0.01)$.

Changes during Perfusion of the Hypertonic Solution with Bicarbonate. Total $\mathrm{CO}_{2}$ content of the perfusion solution did not change significantly in either the jejunal or ileal segments of the 2-wk-old rats. However, in the 8 -wk-old rats, perfusion solution total $\mathrm{CO}_{2}$

\begin{tabular}{|c|c|c|c|c|c|c|c|}
\hline \multirow[b]{3}{*}{ Age (days) } & \multirow{3}{*}{$\begin{array}{l}\text { No. of rats stud- } \\
\text { ied' }^{\text {sed }}\end{array}$} & \multirow{3}{*}{$\begin{array}{c}\text { Body wt } \\
\text { (g) }\end{array}$} & \multirow[b]{3}{*}{ Length $(\mathrm{cm})$} & \multicolumn{3}{|c|}{ Small intestinal segment } & \\
\hline & & & & \multicolumn{2}{|c|}{ Full-thickness wall } & \multicolumn{2}{|c|}{ Mucosal scrapings } \\
\hline & & & & $\begin{array}{l}\text { Wet wt } \\
(\mathrm{mg})\end{array}$ & $\begin{array}{l}\text { Wet wt } \\
(\mathrm{mg} / \mathrm{cm})\end{array}$ & $\begin{array}{c}\text { Wet wt } \\
(\mathrm{mg})\end{array}$ & $\begin{array}{l}\text { Water content } \\
\text { (mg/100 mg) }\end{array}$ \\
\hline \multicolumn{8}{|l|}{ Jejunum } \\
\hline $14-15$ & 50) & $30 \pm 1^{2}$ & $14.1 \pm 0.7$ & $236 \pm 16$ & $16.8 \pm 0.7$ & $138 \pm 14$ & $79.3 \pm 0.6$ \\
\hline 2122 & 13 & $42 \pm 1$ & $15.7 \pm 0.8$ & $316 \pm 25$ & $20.8 \pm 1.3$ & $191 \pm 20$ & $81.2 \pm 0.3$ \\
\hline 56 & 51 & $215 \pm 3$ & $17.6 \pm 1.5$ & $1402 \pm 150$ & $79.0 \pm 1.2$ & $1021 \pm 73$ & $83.1 \pm 0.3$ \\
\hline \multicolumn{8}{|l|}{ Ileum } \\
\hline $14-15$ & 50 & $30 \pm 1$ & $16.3 \pm 0.9$ & $291 \pm 23$ & $17.6 \pm 0.7$ & $166 \pm 18$ & $80.4 \pm 0.4$ \\
\hline $21-22$ & 13 & $42 \pm 1$ & $16.6 \pm 1.3$ & $341 \pm 22$ & $21.0 \pm 1.2$ & $198 \pm 19$ & $81.6 \pm 0.4$ \\
\hline 56 & 51 & $215 \pm 3$ & $15.2 \pm 0.8$ & $1026 \pm 78$ & $67.0 \pm 1.0$ & $713 \pm 44$ & $83.1 \pm 0.3$ \\
\hline
\end{tabular}

Table 1. Body weight of the rats and measurements of the intestinal segments perfused

'At each age, five to seven normal rats were used for study of each one of the perfusion solutions.

2 Mean \pm S.E. 
Table 2. Rates of transport of bicarbonate and water in the segments perfused

Bicarbonate transport (mmols/hr/g dry wt mucosa)

\begin{abstract}
Solution with hicarbonate
\end{abstract}

Age (da
Jejunum
$14 \cdot 15$
$21-22$
56

\section{Solutionic}

Hypertonic

Solution free of bicarbonate

Isontonic Hypertonic

Water transport (m)

Isotonic Hypertonic

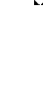

Solution free of hicarbonate

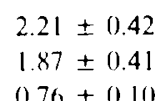

$$
-2.01 \pm 0.50
$$

$-0.23 \pm 0.04$

$-1.12 \pm 0.16$

$-4 \pm 4$
$8 \pm 4$
$2 \pm 1$

$-114 \pm 16$

$-56 \pm 23$

$-39 \pm 8$

$3 \pm 2$

$0.15 \pm 0.22-0.11 \pm 0.04-0.05 \pm 0.03$

$-15 \pm 4$

Ileum

$\begin{array}{lr}1415 & 0.32 \pm 0.55 \\ 21-22 & 0.35 \pm 0.25 \\ 56 & -0.71 \pm 0.11\end{array}$

Segment perfused

Mean \pm S.E

$\begin{array}{rrrr}-1.41 \pm 0.51 & -0.85 \pm 0.23 & -0.69 \pm 0.16 & -4 \pm 3 \\ -1.42 \pm 0.35 & -0.78 \pm 0.09 & -0.54 \pm 0.16 & 6 \pm 3 \\ & & \pm 1\end{array}$

$-6.3 \pm 18$

$-118 \pm 43$

$-30 \pm 0$
$-138 \pm 40$

$15 \pm 1$

$-39 \pm 11$ content decreased in the jejunal segment and increased in the ileal segment. Both changes were by about 20 to $25 \%$ of initial values $(P<0.01)$.

During perfusion of the isotonic and hypertonic solution free of bicarbonate in both the jejunal and ileal segments of the 2- and of the 8 -wk-old rats, perfusion solution total $\mathrm{CO}_{2}$ content and $\mathrm{PCO}_{2}$ increased by two- to eight-fold over initial values $(P<0.01)$. The $\mathrm{pH}$ of the perfusion solutions varied in accordance with the changes in the total $\mathrm{CO}_{2}$ content and $\mathrm{PCO}_{2}$ of the perfusion solutions.

\section{TRANSPORT OF: BICARBONATE:}

Rate of transport of bicarbonate expressed on the basis of dry weight of the mucosal scrapings of the segments are shown in Table 2. Rates of transport expressed on the basis of wet weight of segments and the wet weight of the mucosal scraping had the same relationships as noted in Table 2 . During perfusion of the isotonic solution with bicarbonate, there was net absorption of bicarbonate (+ values) in the jejunal segments of rats at all three age periods. Rates of absorption were significantly greater in the jejunal segments of the 2- and 3-than in those of the 8 -wk-old rats $(P<0.01)$. In the ileal segments, there was net absorption of bicarbonate in the 2 - and 3 -wk-old rats and net secretion (-values) of bicarbonate in the 8-wk-old rats. Addition of glucose (5 mmoles/liter) or acetazolamide $(10 \mathrm{mmoles} / \mathrm{liter})$ to the perfusion solutions did not influence rate of net transport of bicarbonate in the jejunal or in the ileal segments at any of the three age periods and are not presented in the table.

Perfusion of the hypertonic solution with bicarbonate caused net secretion of bicarbonate into the lumen of both the jejunal and the ileal segments of 2 -wk-old rats. In the 8 -wk-old rats. there was minimal net absorption in the jejunal segment and net secretion in the ileal segment. Rates of transport during perfusion of the hypertonic solutions with bicarbonate were significantly different $(P<0.01$ to 0.005$)$ than corresponding rates during perfusion of the isotonic solutions with bicarbonate.

During perfusion of the solutions free of bicarbonate, there was net secretion of bicarbonate into the lumen of the jejunal and of the ileal segments in both the 2- and the 8-wk-old rats. In the jejunal segments of the 2 -wk-old rats, rates of net secretion were significantly greater during perfusion of the hypertonic solution than during perfusion of the isotonic solution $(P<0.01)$ free of bicarbonate. In the ileal segments of the 2 -wk-old rats and in both segments of the 8 -wk-old rats, net secretion rates were not significantly influenced by increasing the osmolality of the solutions free of bicarbonate.

\section{TRANSPORT OF: WATER}

During perfusion of the isotonic solution, water was secreted into the lumen of the segments in the 2-wk-old rats and absorbed from the lumen in the 3-and 8-wk-old rats. In comparison to perfusion of the isotonic solution, perfusion of the hypertonic solution significantly incresed net water secretion in both the jejunal and ileal segments of the 2 -wk-old rats $(P<0.005)$ and reversed net absorption to net secretion in the 8 -wk-old rats. Rates of net secretion of water were severalfold greater in segments of the 2-wk-old than in the corresponding segments of the 8 -wk-old rats $(P<0.01)$. In a previous similar study of rats $(19)$, we showed that recovery of phenol red after in vivo perfusion of the segments of the jejunum and ileum was 96 to $98 \%$; in both 2- and 7-wk-old rats. These findings indicated that the differences in rates of transport of water between segments of the 2- and 8-wk-old rats were not due to major differences in absorption of phenol red in intestinal segments of the rats studied.

\section{A(II)-BASH STATUS OH: THE RATS}

At the end of the 2-hr perfusion period with the isotonic solution. there was no significant change in the acid-base status of the 2- and 8-wk-old rats. Blood $\mathrm{pH}$ (mean $\pm \mathrm{S}$. E.) in the 2-wk-old rats was $7.34 \pm 0.03$. and in the 8 -wk-old rats, it was $7.43 \pm 0 .(12$. These were not very different from values in unperfused rats of similar age, $7.41 \pm 0.04$ and $7.42 \pm 0.01$. respectively. At the end of the 2 -hr perfusion period with the hypertonic solutions with bicarbonate, the 2 -wk-old rats developed relatively severe metabolic acidosis. $\mathrm{pH} 7.19 \pm 0 .\left(22\right.$ and $\mathrm{PCO}_{2} 29 \pm 2 \mathrm{~mm} \mathrm{Hg}$. but the 8 -wk-old rats did not $(\mathrm{pH} 7.46 \pm 0.03$ and $\mathrm{PCO} .28 \pm 2 \mathrm{~mm} \mathrm{Hg}$ ). Blood $\mathrm{PO}$. in the 2- and 8 -wk-old rats showed a mean of 91 to 105 $\mathrm{mm} \mathrm{Hg}$.

THE (INII)IRI: ( TIONAI FI IIXIS OH: BIC ARBONATI

The LM and ML fluxes were approximated during perfusion of the isotonic solution containing bicarbonate. In the jejunal segments, both unidirectional fluxes (mmoles/hr/g dry wt) were over 2 -fold and significantly greater in the 2 -wk-old (mean \pm S.E.: $L M$. $2.80 \pm 0.58: \mathrm{ML}, 0.70 \pm 0.38$ ) than in the 8 -wh-old (LM, $0.97 \pm$ $0.11: \mathrm{ML}, 0.20 \pm 0.05)$ rats. In the ileal segments. LM flux was significantly greater in the 2 -wk-old $(1.94 \pm 0.40)$ than in the 8 wk-old $(0.86 \pm 0.11)$ rats $(P<0.01)$ : however, the ML fluxes were not significantly different $(1.49 \pm 0.55$ and $1.51 \pm 0.15$, respectively). The LM and ML fluxes expressed on the basis of wet weight of the segments or on the hasis of wet weight of the mucosal scraping had the same relationships as those expressed on the dry weight of the mucosal scraping.

\section{DISC USSION}

Findings in the 8 -wk-old rats of the present study were similar to those reported in adult rats, indicating net absorption of bicarbonate in the jejunum and net secretion in the ileum $(11,14)$. In the infant rats, the pattern of transport of bicarbonate was different 
than those in the 8 -wk-old rats, suggesting a change in the mechanism(s) of transport of bicarbonate during maturation of the small intestine. In the jejunum, the relatively much higher rates of net absorption of bicarbonate in the 2-wk-old rats declined to the lower levels noted in 8-wk-old rats. In the ileum, the minimal net absorption present early in life changed to significant net secretion later in life. The above changes appeared to take place gradually and to have occurred sometime after weaning (3 wk of age) in the rat. The magnitude of the approximated unidirectional fluxes of bicarbonate along the length of the intestine also indicated changes during maturation. At 2 wk of age, the LM flux of bicarbonate (mmoles $/ \mathrm{hr} / \mathrm{g}$ dry wt of mucosal scrapings) showed a proximal-to-distal gradient. This gradient was lost by 8 wk of age. mainly due to the decrease in the LM flux in the jejunum (from 2.80 to 0.97). The reverse or ML flux showed a distal-to-proximal gradient. This gradient persisted during maturation, but the magnitude of the gradient increased with age and was mainly due to the decline in the ML flux in the jejunum (from 0.7 to 0.2$)$

In the jejunum, the changes in acid-base status (decrease in $\mathrm{pH}$ and total $\mathrm{CO}_{2}$ content and increase in $\mathrm{PCO}_{2}$ ) noted during perfusion of the isotonic solution with bicarbonate were consistent with the theory accepted by most investigators that bicarbonate is absorbed as $\mathrm{CO}$. resulting from an exchange of $\mathrm{Na}^{+} \cdot \mathrm{H}^{+}$between the lumen and mucosa $(3,4,7,10,11,16)$. The secreted $\mathrm{H}^{+}$ combines with $\mathrm{HCO}_{3}$ to produce $\mathrm{H}_{2} \mathrm{CO}_{3}$ which dissociates into $\mathrm{CO}_{2}$ and $\mathrm{H}_{2} \mathrm{O}$. The greater rate of net $\mathrm{HCO}_{3}$ absorption in the jejunal segments of the 2-and 3-wk-old than in those of the 8-wkold rats could have been due to a greater rate of $\mathrm{Na}^{+}-\mathrm{H}^{+}$exchange in the segments of the younger rats. Inasmuch as the $\mathrm{Na}^{+}-\mathrm{H}^{+}$ exchange mechanism may account for only 15 to $57 \%$ of the $\mathrm{HCO}_{3}$ absorbed in the jejunum (7, 12), differences in other mechanism(s) could have also been responsible for the age-related variation in $\mathrm{HCO}_{3}$ absorption.

The concentration gradient of bicarbonate between the lumen of the jejunum (23 to 24 mmoles/liter) and the plasma (about 18 mmoles/liter) was only slightly higher in the 2-wk-old $(6$ mmoles/ liter) than in the 8 -wk-old ( 5 mmoles/liter) rats, it would not be expected that the three-fold difference in rates of net bicarbonate absorption was due to the differences in concentration gradients of bicarbonate across the segment mucosa.

Inasmuch as absorption of bicarbonate is not influenced by alterations in the transepithelial potential difference (12) and under conditions similar to those in the present study the potential difference across the intestinal epithelium appeared to be minimal (7. 12), it seems unlikely that the differences in rate of absorption of bicarbonate in the jejunum of the 2- and 8-wk-old rats could have been due to potential differences across the segment epithelium.

In the ileum, bicarbonate appears to be actively transported from the mucosa into the lumen $(2,3,5,6,14)$. Most investigators have favored the concept that bicarbonate is secreted into the lumen in exchange for chloride absorption $(5,6,11,15)$. The finding that in the ileal segments of the 2- and 3-wk-old rats there was absorption of bicarbonate rather than secretion suggested that the $\mathrm{HCO}_{3}-\mathrm{Cl}$ exchange mechanism was less active in the ileum of the 2-than in that of the 8-wk-old rats. However, the agerelated variations could have been due to other differences in mechanism(s) of bicarbonate and chloride transport, such as a process in which $\mathrm{H}^{+}$transport is governed in part by rate of $\mathrm{Cl}$ absorption or an exchange of hydroxyl ion for chloride (6).

Glucose in this study at a concentration of 5 mmoles/liter and in our previous study at a concentration of $15 \mathrm{mmoles} / \mathrm{liter}$ (17) did not influence rate of transport of bicarbonate. Acetazolamide in doses larger than that used in the present study $(10$ mmoles/ liter) decreased the rate of absorption of bicarbonate in the jejunum and increased its rate of secretion in the ileum $(9,11)$. The finding of the present study that acetazolamide did not effect rate of transport of bicarbonate either in the jejunum or in the ileum is consistent with the suggestion that whatever the biochem- ical basis of the ionic exchanges which constitutes the processes of salt and bicarbonate transport in the small intestine. the presence of carbonic anhydrase may not be obligatory (1).

During perfusion of the isotonic solution free of bicarbonate. the concentration gradient of bicarbonate between plasma (about $18 \mathrm{mmoles} / \mathrm{liter}$ ) and lumen ( 1 to $7 \mathrm{mmoles} / \mathrm{liter}$ ) probably served as a driving force to cause net secretion of bicarbonate into the lumen of the perfused segments. In both the 2- and 8-wk-old rats, the higher rates of net secretion in the ileal than in the jejunal segments (Table 2) were not completely unexpected because the ML flux of bicarbonate was greater in the ileum than in the jejunum. The higher rate of net secretion of bicarbonate in the jejunum of the 2-than in that of the 8 -wk-old rats during perfusion of the isotonic and of the hypertonic solutions suggested greater permeability of the jejunal mucosa to bicarbonate in the 2-than in the 8 -wk-old rats and was consistent with the almost two-fold greater unidirectional fluxes of bicarbonate in the jejunum of the 2- than in that of 8 -wk-old rats. The response of the intestinal segments to perfusion of the hypertonic solutions was different at the two age periods. In 2 -wk-old rats, the jejunal segment did not appear to adjust to the osmolality of the perfusion solution, and rate of net secretion of bicarbonate increased in proportion to the rise in osmolality of the perfusion solution (Table 2). However. the ileal segment of the 2-wk-old rats and both segments of the eight-wk-old rats responded to increased luminal osmotic pressure in a way to decrease loss of bicarbonate into the lumen, and net secretion rates were slightly lower during perfusion of the hypertonic than the isotonic solutions free of bicarbonate. The reason why this response was not as effective during perfusion of the hypertonic solution containing bicarbonate is not known.

Because of the greater permeability of the intestinal mucosa to bicarbonate in the 2 - than in the 8 -wk-old rats and because of the lack of response to luminal hypertonicity of the jejunum in the two-wk-old rats, net loss of bicarbonate during perfusion of the hypertonic solution was relatively greater in the infant than in the older rats (solution with bicarbonate: 2 -wk-old, $77 \mu$ moles/hr: 8 wk-old, $175 \mu$ moles $/ \mathrm{hr}$ ). The total loss when compared on the basis of $100 \mathrm{~g}$ body weight was almost 2 -fold greater in the 2-wkold $(2 \mu$ moles $/ \mathrm{hr})$ than in the 8 -wk-old $(1 \mu \mathrm{mole} / \mathrm{hr})$ rats. The older rats appeared to have compensated for the loss, but the younger rats failed to do so and became severely acidotic.

\section{REFEREN(ES ANI) NOTES}

1. Carter. M. D. and Parsons. D. S.: (arbonic anhydrase activity of mucosa of small intestine and colon. Nature (Lond.). 219: 176 (1968)

2. Curran. P. D.. and Solomon. A. K.: Ion and water fluxes in the ileum of rats. $J$ (ien. Physiol. 4): 143 (1957).

3. Fordiran. J. S. Rector, F. C.. Jr... and (arter. N. W.: The mechanisms of sodium aborption in the human small intestine. J. Clin. Invest.. 47:884 (1968).

4. Hamilun. J. D.. Dawson. A. M.. and Webb. J. P. W.: Observation. upon small gut "mucosal" $\mathrm{pO}$ : and $\mathrm{p}\left(\mathrm{CO}_{2}\right.$ in anesthetized dogs. (iastroenterology. 55: 52 $(1968)$

5 Huhel. K. A.: Bicarhonate secretion in rat ileum and its dependence on intraluminal chloride. Am. J. Physiol.. 213: 1409 (1967).

6. Hubel. K. A.: Effect of Juminal chloride concentration on bicarbonate secretion in rat ileum. Am. J. Physiol., 21?: 40 (1469)

7. Hubel. K. A.: Fffect of luminal sodium concentration on bicarbonate absorption in rat jejunum. J. ( lin. Invest.. 5:: 3172 (1973).

8. Huntsherger. D. V., and L.eaverton. P. E.: Statistical Inference in the Biomedical Sciences p. 127. (Allyn \& Bacon. Inc., Boston. 1970)

9. Kinney. V. R., and Code. ( . F.: Canine ileal chloride absorption: effect of carbonic anhydrase inhibitor on transport. Am. J. Physiol. 20?: 998 (1964).

10. Mc(jee. L. ('.. and Hastings. A. B.: The carbon dioxide tension and acid-base halance of jejunal secretions in man. J. Biol. ('hen.. 142: 893 (1942).

11. Parsons. D. S.: The absorption of hicarbonate-saline solutions by the small intestine and colon of the white rat. Q. J. Exp. Physiol. Cogn. Med. Sci. 4l: $410(1956)$.

12. Podesta. R. B.. and Mettrick. D. R.: HCO, transport in rat jejunum: relationship to $\mathrm{NaCl}$ and $\mathrm{H}_{2} \mathrm{O}$ transport in vivo. Am. J. Physiol.. 23: E62 (1977)

13. Schedl. H. P.. and Clifton. J. A.: Small intestinal absorption of steroids. (jastroenterology. 41: 491(1965).

14. Swallow, J. H.. and Code, C. F.: Intestinal transmucosal fluxes of hicarbonate. Am. J. Physiol., 212: 717 (1967).

15. Turnherg. L. A. Bieberdorf. F. A. Morawski. S. ( $;$., and Fordtran. J. S. Interrelationships of chloride. bicarbonate, sodium and hydrogen transport in human ileum. J. Clin. Invest., 49: 557 (1970). 
16. Turnberg. L. A. Forderan. J. S. Carter. N. W. and Rector. F. C.. Jr. Mechanism of hearbonate aborptom and its relationship to sodium tranoport in the human jejunum. J. (lin. Invest. fy: 548 (1970).

17. Younosat. M. K.: In vio transport of water and electrolytes in the infant rat small intestine. Proc. Soc. Exp. Biol. Med.. Inot: $192(1979)$

Ix Younoszal, M. K.. and I.vnch, A.: In vivo D-glucose absorption in the developing rat small intestine. Pediatr. Res.. 1) $130(1975)$

19. Younosat. M. K.. Sapiro, R. S.. and Laughlin, M: Maturation of the jejunum and ileum in rats: water and electrolvte transport during in vio perfusion of

(inpright : I 480 International Pediatric Research Foundation. Inc

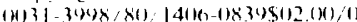

hypertunic solutions. J. (Cin. Invest. o2: 271 (197x).

21). Requests for reprints should he addressed to: M. K. Younoszai. M. D). University of lowa Hospitals and (linics. Department of Pediatrics. lowa (ity. 1.4 52242 (USA).

21. This research was supported in part by Research (irant HD 08227. Department of ( hild Health and Human Development and by a grant from the ('ollege of Medicine. I niversity of lowa.

22. Received for publication April 30. 1974.

23. Accepted for publication September 25, 1479. 